Abstract-To clarify the ontogenetic changes in antipredator behavior of juvenile white rockfish (Sebastes cheni), effects of light intensity (0.1, $1,10,100,1000$, and 10,000 lx) and body size $(23.4,30.3,41.1,49.4$ and $58.6 \mathrm{~mm}$ in total length [TL]) on swimming (cruising [swimming] speed [CS] and burst [swimming] speed $[\mathrm{BS}]$ ) and schooling behavior (nearest neighbor distance [NND] and separation angle [SA]) were examined under laboratory conditions. The CS was higher under higher light intensities for all length classes. The BS increased with increases in fish body size at the highest light intensity although there was no significant effect of body size at the lowest light intensity. The NND was largest for the smallest fish-size class at all light intensities. The effects of light intensity and fish body size on SA were not significant. Schooling behavior of the juvenile white rockfish was determined to begin to develop at body sizes $>30$ $\mathrm{mm}$ TL. In this study, we found the ability of juvenile white rockfish to avoid predation through schooling behavior to be minimal in comparison with other species because the instinct appears to not be well developed during the early postsettlement period (20-30 mm TL).

Manuscript submitted 7 January 2014. Manuscript accepted 21 January 2015. Fish. Bull. 113:121-128 (2015). doi: 10.7755/FB.113.2.2

The views and opinions expressed or implied in this article are those of the author (or authors) and do not necessarily reflect the position of the National Marine Fisheries Service, NOAA.

\title{
Development of swimming speed and schooling behavior of juvenile white rockfish (Sebastes cheni) in relation to ambient light intensity
}

\author{
Hikaru Nakano' \\ Koji Hirakawa ${ }^{2}$ \\ Jun Shoji (contact author) ${ }^{1}$ \\ Email address for contact author: jshoji@hiroshima-u.ac.jp \\ 1 Takehara Fisheries Research Laboratory \\ Hiroshima University \\ 5-8-1 Minato-machi \\ Takehara, Hiroshima 725-0024, Japan \\ 2 Hiroshima Prefectural Sea Farming Center \\ 185-12 Takasaki \\ Takehara, Hiroshima 729-2313, Japan
}

Vegetated habitats, such as seagrass and macroalgae beds, are recognized as critical habitat for a variety of fish species because they serve as feeding grounds and refuges from predation for early life stages of fishes (Heck and Orth, 2006). However, observations of higher abundances of piscivorous fishes during night than during the day in recent field surveys have indicated that larval and juvenile fishes are exposed to higher rates of mortality (owing to predation at night in vegetated habitats) than rates of mortality owing to predation during the day in these habitats (Hindell et al., 2000; Guest et al., 2003). In addition, stomach content analyses of piscivorous fishes, coupled with tethering experiments in seagrass beds in the Seto Inland Sea off southwestern Japan, have revealed that the predation rate on juvenile white rockfish (Sebastes cheni) by piscivorous fishes was significantly higher at night than during the day (Kinoshita et al., 2012). Throughout this article, we refer to Sebastes cheni as "white rockfish" to reduce confusion with other common names applied to this and other spe- cies of Sebastes. For example, S. che$n i$ has been called "black rockfish" in other publications, but that common name is used in the United States and Canada for a different species, $S$. melanops. Other common names for S. cheni are "rockfish," "Japanese black rockfish," "white seapearch" and "shiro-mebaru."

The recent observations noted in the previous paragraph suggest that a re-evaluation is needed for a common understanding that aquatic macrophytes have a function as a refuge from predation for juvenile fishes (e.g., Petr, 2000)—a notion that has been established mainly on the basis of observations during the day. Comprehensive analysis of predatorprey interactions during both day and night, with a focus on possible diurnal changes in both predator and prey behaviors, would help us better understand the survival mechanisms of early life stages of fishes in these habitats.

Rockfishes (Sebastes spp.) are distributed widely in coastal waters of the western North Pacific and are commercially and recreationally important species (Love et al., 1991; 
Jones et al., 2012). A recent taxonomic review of specimens considered to be Sebastes inermis has provided evidence that they are a species group of 3 congeners: $S$. inermis, S. ventricosus, and $S$. cheni on the basis of morphological and genetic analyses (Kai and Nakabo, 2008). Sebastes cheni dominates the fish community of the vegetated habitats (seagrass and macroalgal beds) in coastal waters of the Seto Inland Sea, off southwestern Japan (Kamimura and Shoji 2009; Kamimura et al., 2011). Juveniles settle in vegetated habitats at $\sim 20 \mathrm{~mm}$ in total length (TL) and grow to $60 \mathrm{~mm}$ TL in their first summer. Juveniles of several Sebastes species have been shown to exhibit a strong association with seagrass and macroalgae during the postsettlement period, inhabiting substrates, such as kelp and rocky reef, until they reach a body size of $>60 \mathrm{~mm}$ TL (Love et al., 1991, 2002; Plaza et al., 2002; Dauble et al., 2012). Recent surveys have indicated that survival during the substrate-associated period has the potential to determine the abundance of regional Sebastes stocks in the eastern and western North Pacific (Adams and Howard, 1996; Laidig et al., 2007; Kamimura and Shoji, 2013).

Predation is considered one of the most important sources of mortality during the early life stages of fishes (Houde, 1987). The instantaneous predation rate of juvenile white rockfish during night in seagrass beds in the Seto Inland Sea was $\sim 5.1 \%$ in a study conducted in 2009-2011 (Kinoshita et al., 2012). Furthermore, size-selective predation, by which white rockfish juveniles $<30 \mathrm{~mm}$ TL were eaten more frequently than those $>30 \mathrm{~mm}$ TL, was observed during night in the macroalgal bed (Kinoshita et al., 2014). Generally, ontogenetic improvement in swimming and schooling behaviors during the early life of fishes is believed to enhance fish survival by the development of antipredator behavior (Masuda and Tsukamoto, 1998). Information on how the interactions between juvenile white rockfish at various sizes and diurnal changes in their behavior affect predation probability is indispensable for the formation of a comprehensive understanding of survival mechanism in juvenile habitats.

In our study, effects of body size and light intensity on swimming and schooling behaviors of juvenile white rockfish were examined under laboratory conditions. We hypothesized that swimming and schooling behaviors develop during the juvenile period and that the effect of light condition on these behaviors begins to operate during this period. In addition, antipredator behaviors among species were compared by using data reported for other species in previous studies.

\section{Materials and methods}

\section{Experimental fish}

White rockfish larvae and juveniles reared at the $\mathrm{Hi}$ roshima Prefectural Farming Fisheries Center were

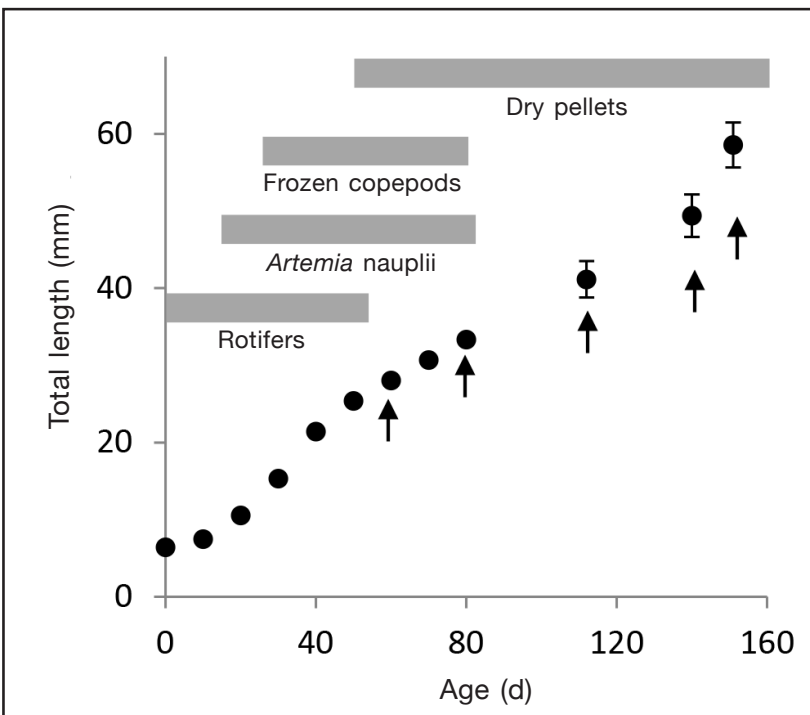

Figure 1

Growth of larval and juvenile white rockfish (Sebastes cheni) in the laboratory experiments conducted in 2012 to determine the development of swimming speed and schooling behavior of white rockfish in relation to light intensity. Error bars indicate standard deviation, and arrows indicate day of experiment. Shaded bars indicate feeding schedule, during which rotifers (Brachionus sp.) were supplied from day 0 to day 55 , brine shrimp (Artemia sp.) nauplii from day 13 to day 80, frozen copepods from day 25 to day 80 , and dry pellets from day 50 to day 151 .

used for our experiments. Larvae were extruded from adult white rockfish (4-6 years old) on 5-9 January 2012. Mean larval TL at extrusion was $6.4 \mathrm{~mm}$. Rotifers (Brachionus sp.) were given to fish as feed from day 0 to 55 , and the food supply for fish included brine shrimp (Artemia sp.) nauplii from day 13 to 80 , frozen copepods from day 25 to day 80, and dry pellet from day 50 to day 151 (Fig. 1). Water temperature of the rearing tanks increased from $11^{\circ} \mathrm{C}$ to $17^{\circ} \mathrm{C}$ during the experiments. To investigate the ontogenetic changes in swimming and schooling behaviors, experiments were conducted with fish in 5 length classes, covering the postsettlement stage (20$60 \mathrm{~mm}$ TL): 1) $23.4 \mathrm{~mm}$ TL (standard deviation [SD] 1.4) by day $61 ; 2) 30.3 \mathrm{~mm}$ TL (SD 3.1) by day 78 ; 3 ) $41.1 \mathrm{~mm}$ TL (SD 2.4) by day 112 ; 4) $49.4 \mathrm{~mm}$ TL (SD 2.8 ) by day 140 ; and 5) $58.6 \mathrm{~mm}$ TL (SD 2.9) by day 151 (Fig. 1).

Lux (lx) was used as the light intensity unit for comparison of behaviors of other fish species in previous studies. Six levels of light intensity $(0.1,1$, $10,100,1000$, and $10,000 \mathrm{~lx}$ ) were set by using 1-5 incandescent bulbs (40 or $500 \mathrm{~W}$ ) and translucent black vinyl sheets, which allowed some light to pass through them, in an experimental room $(1.8 \times 0.9 \times 1.8$ $\mathrm{m})$. Light intensity was measured with a digital light 
meter (400-TST-902, Sanwa Supply Inc. ${ }^{1}$, Okayama, Japan) at the surface of each tank. A video camera (Handycam DCR-DVD505, Sony Corp.) was mounted vertically above the center of the experimental tanks to record fish behavior. Red light was used for observations at 0.1 and $1 \mathrm{~lx}$. Fish were not fed for 1 day before the experiments. No fish died during these experiments.

\section{Experiment 1}

Two circular polycarbonate tanks of different sizes were used for the experiments, and fish were put in one of the tanks depending on fish size. A 30-L tank, with a water depth of $28 \mathrm{~cm}$, was used for the experiment with fish at $23.4,30.3$, and $41.1 \mathrm{~mm} \mathrm{TL}$, and a 100-L tank, with a water depth of $40 \mathrm{~cm}$, was used for the experiment with fish at 49.4 and $58.6 \mathrm{~mm}$ TL. Fish behavior was observed under 6 light levels $(0.1,1$, $10,100,1000$, and 10,000 lx). Twenty fish in each size group were introduced into each tank and were acclimated for $1 \mathrm{~h}$ at $100 \mathrm{~lx}$, a level that approximates the light intensity in their natural habitat (seagrass and macro-algal beds) during day. Fish were acclimated at each light intensity for 30 min before each observation.

Fish behavior was recorded for $5 \mathrm{~min}$ by the video camera. Fish behavior observed in the $10 \mathrm{~s}$ of video collected immediately after the first 1 min of recording was used for analysis of cruising speed (CS). Two parameters of schooling behavior, nearest neighbor distance (NND) and separation angle (SA), were defined according to the method described by Masuda et al. (2003). NND and SA are descriptors of parallel orientation and aggregation, respectively, calculated from a still frame of video at $1 \mathrm{~min}$ from the start of recording. NND was divided by TL to facilitate the comparison among different size groups. SA, ranging from $0^{\circ}$ to $180^{\circ}$, was expected to be $90^{\circ}$ when fish were located in a random direction and was expected to decrease as they developed a parallel orientation. Aeration was stopped during this experiment. Individual fish were used in only one treatment and were not reused in this study.

\section{Experiment 2}

Burst [swimming] speed (BS) was measured by using sound stimuli according to the methods in Masuda et al. (2002). A 10-L, circular, polycarbonate tank, with a water depth of $15 \mathrm{~cm}$, was used for observations of fish in all size classes. Ten fish were introduced into the tank and were kept for $1 \mathrm{~h}$ at $100 \mathrm{~lx}$ for acclimation. The fish were acclimated for 30 min under experimental light intensity before the start of each experiment. A sound stimulus was produced with a steel nut (10 g) hung by a string $(40 \mathrm{~cm})$; the nut was released from a

\footnotetext{
${ }^{1}$ Mention of trade names or commercial companies is for identification purposes only and does not imply endorsement by the National Marine Fisheries Service, NOAA.
}

distance of $20 \mathrm{~cm}$ from the side of the tank to hit the tank wall. The experiment was conducted at the lowest and highest light intensities (0.1 and 10,000 lx). The BS was calculated from the distance of fish movement for $0.25 \mathrm{~s}$ after the sound stimulus. Aeration was stopped during the experiment. Individual fish were used in only one treatment and were not reused in this study.

\section{Statistic}

The CS, NND, and SA of juvenile white rockfish were compared at the different light intensities (6 levels) within the same size class and among results for fish in different size classes within the same light intensity by means of Kruskal-Wallis tests with Steel-Dwass's tests for multiple comparisons. BS was compared for fish at the different light intensities (2 levels) within the same size class by the Wilcoxon test and among results for fish in the different size classes within the same light intensity by the Kruskal-Wallis test with Steel-Dwass's test for multiple comparisons. All these statistical analyses were performed with the software programs R, vers. 3.1.1 (R Core Team, 2014) and JMP, vers. 8, (SAS Institute Inc., Cary, NC).

\section{Results}

Mean CS was highest under higher light intensities (1000 or $10,000 \mathrm{~lx})$ within all size classes of fish (Fig. 2). There was a significant effect of light intensity on CS in each fish size class (Kruskal-Wallis test with Steel-Dwass's test for multiple comparisons: $P<0.001$ ). For fish within the same light intensity, size had a significant effect on CS. Across all light intensities, the CS of fish in the 2 largest size classes $(49.4$ and $58.6 \mathrm{~mm}$ TL) was significantly larger than the CS of fish in the smaller size classes $(P<0.001)$.

Mean NND decreased as fish grew. At 23.4 and 30.3 $\mathrm{mm}$ TL, the NND under $0.1 \mathrm{~lx}$ was significantly greater than that under $100 \mathrm{~lx}$ (Kruskal-Wallis test with SteelDwass's test for multiple comparisons: $P<0.001$; Fig. 3). Light treatment had no significant effect on NND in the three largest fish size classes $(41.1,49.4$, and 58.6 $\mathrm{mm}$ TL: $P>0.05)$. Within the same light intensity, the NNDs of the one (23.4 mm TL under 1 and $10 \mathrm{~lx}$ ) or two smallest size classes (23.4 and $30.3 \mathrm{~mm}$ TL under 0.1 and $10,000 \mathrm{~lx}$ ) were significantly greater than those of other size classes $(P<0.001)$.

The variability in SA within size and light-intensity groups was large enough that no significant effect of light intensity and fish size was detected (Kruskal-Wallis test: $P>0.05)$. Mean values of SA ranged between $29.8^{\circ}$ (SD 17.7) for fish under $100 \mathrm{~lx}$ and in the size class of $49.4 \mathrm{~mm}$ TL and $102.0^{\circ}$ (SD 51.6) for fish under $0.1 \mathrm{~lx}$ and in the size class of $30.3 \mathrm{~mm}$ TL (Fig. 4).

The effect of fish size on BS was significant under the highest light intensity of 10,000 lx (Kruskal-Wallis test: 


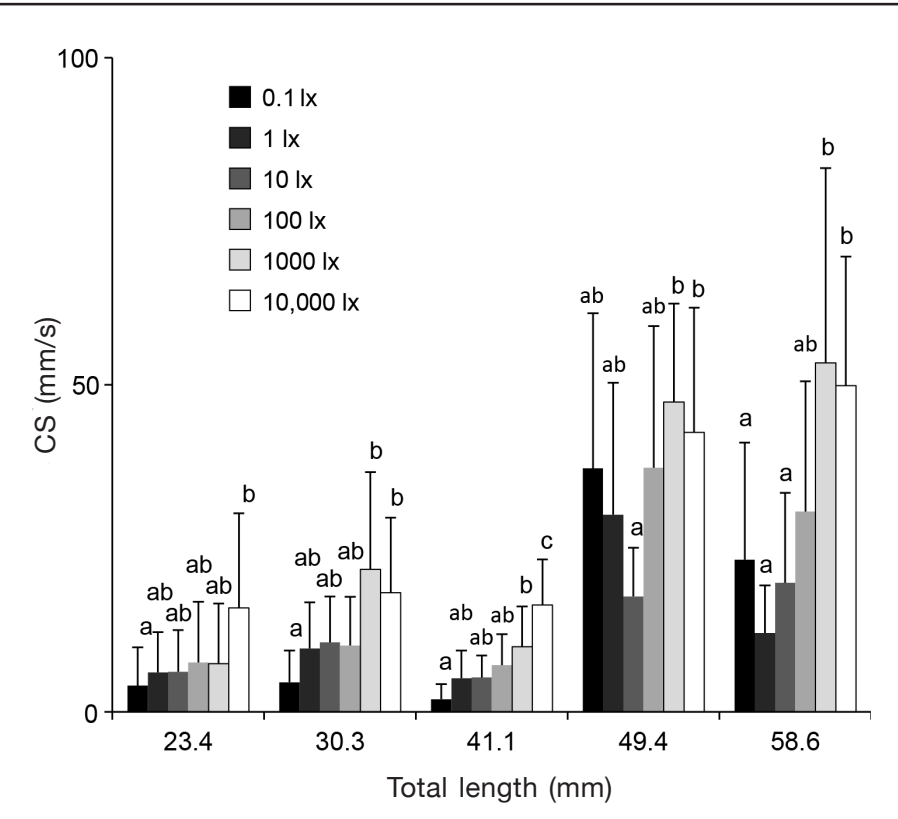

Figure 2

Cruising [swimming] speed (CS; measured in millimeters per second) of juvenile white rockfish (Sebastes cheni) at each size class (total length in millimeters) under different light conditions (from 0.1 to $10,000 \mathrm{~lx}$ ). Error bars indicate standard deviations and letters indicate significant difference in CS among fish at different light conditions within the same size class (Kruskal-Wallis test with Steel-Dwass's test as post-hoc test: $P<0.001)$.

$P<0.05)$, but no size effect was detected under the lowest light intensity of $0.1 \mathrm{~lx}$ (Kruskal-Wallis test: $P>0.05$ ). The BS under the lowest light intensity was significantly lower than BS under the highest light intensity for fish in all size classes tested (Wilcoxon test: $P<0.05$ for fish 23.4-49.4 mm TL and $P<0.01$ for fish $58.6 \mathrm{~mm}$ TL; Fig. 5).

\section{Discussion}

\section{Cruising [swimming] speed}

Changes in CS and adaptation to low-light conditions have been reported in larvae and juveniles of a variety of fish species (Blaxter, 1968; Batty et al., 1990; Miyazaki et al., 2000). In general, CS increases with increases in body size of larval and juvenile fishes. Development of their sensory organs enables larger juvenile fishes to be more active under dark conditions. The results from a comparison of CS among groups of fish of different body sizes in different light conditions in this study indicated that the CS of white rockfish juveniles $<41.1 \mathrm{~mm}$ TL was lower under low light conditions than under greater light intensities. The CS of fish $>41.1 \mathrm{~mm}$ TL increased in relation to speeds of smaller fish at all light intensities.
Mean CS was slowest for juvenile white rockfish under intermediate light intensity in the 2 largest size classes: $49.4 \mathrm{~mm}$ TL under $10 \mathrm{~lx}$ and $58.6 \mathrm{~mm}$ TL under $1 \mathrm{~lx}$. In a previous laboratory experiment, white trevally (Pseudocaranx dentex) juveniles were reported to have swum along the tank wall under total darkness at a CS faster than their CS at a higher light intensity (0.1 lx; Miyazaki et al., 2000). In our study, similar swimming behavior was observed in juvenile white rockfish at 49.4 and $58.6 \mathrm{~mm}$ TL under 0.1 lx (H. Nakano, personal observ.). Swimming may help white rockfish juveniles maintain stable NND under lowest light intensity ( $0.1 \mathrm{~lx}$ in this study) by providing motion cues to the lateral-line sensors of the fish: by contrast, they likely are able to maintain NND under intermediate light conditions (e.g., 1-10 lx) by using their vision. In general, juvenile fishes develop swimming and schooling behaviors under dark conditions with the formation of their lateral lines, a change that enables them to keep favorable distance from other fishes without strong visual cues (Masuda, 2006; Miyazaki et al., 2000). Development of lateral lines at 30-40 mm TL (Suzuki and Aida, 1999) may relate to the increase in CS observed in our study for white rockfish juveniles under the low light conditions (0.1-1 lx in this study). 


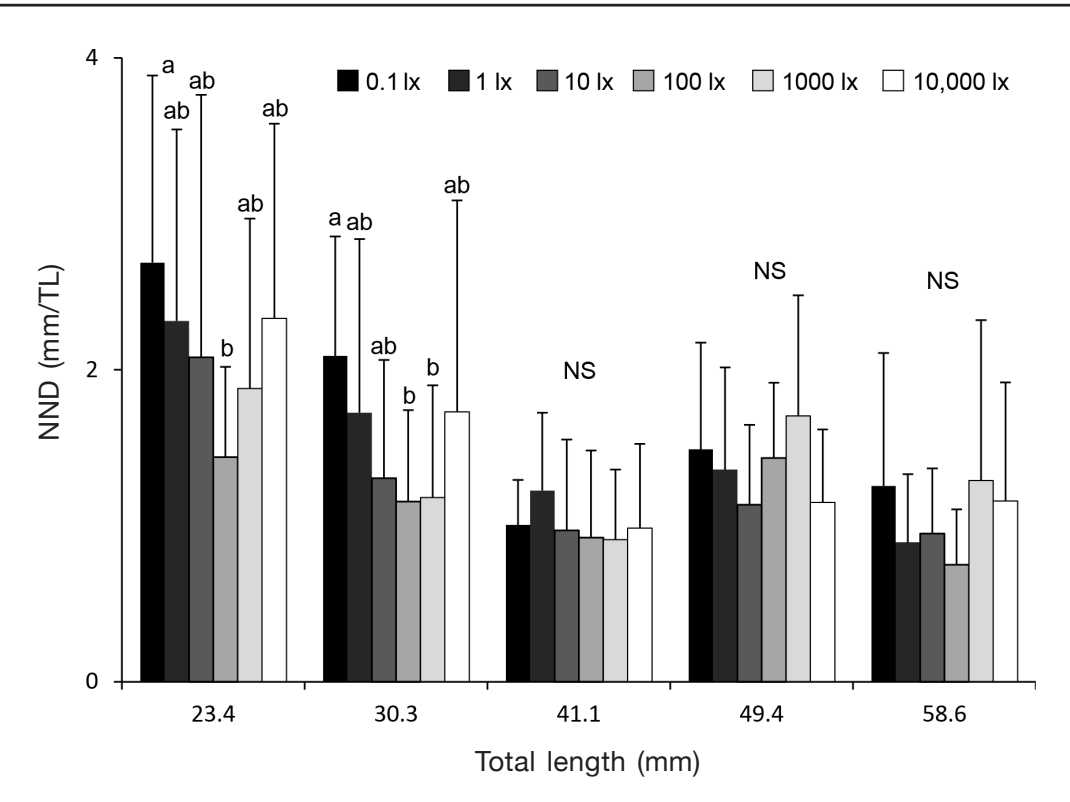

Figure 3

Nearest neighbor distance (NND), which was measured in millimeters and divided by total length (TL) to facilitate comparison among size classes of juvenile white rockfish (Sebastes cheni) at each size class (TL in millimeters) under different light conditions (from 0.1 to $10,000 \mathrm{~lx}$ ). Error bars indicate standard deviations, and letters indicate significant difference in NND among fish at different light conditions within the same size class (Kruskal-Wallis test with Steel-Dwass's test as posthoc: $P<0.001)$. NS indicates that no significant difference was observed for fish within the same size class $(P>0.05)$.

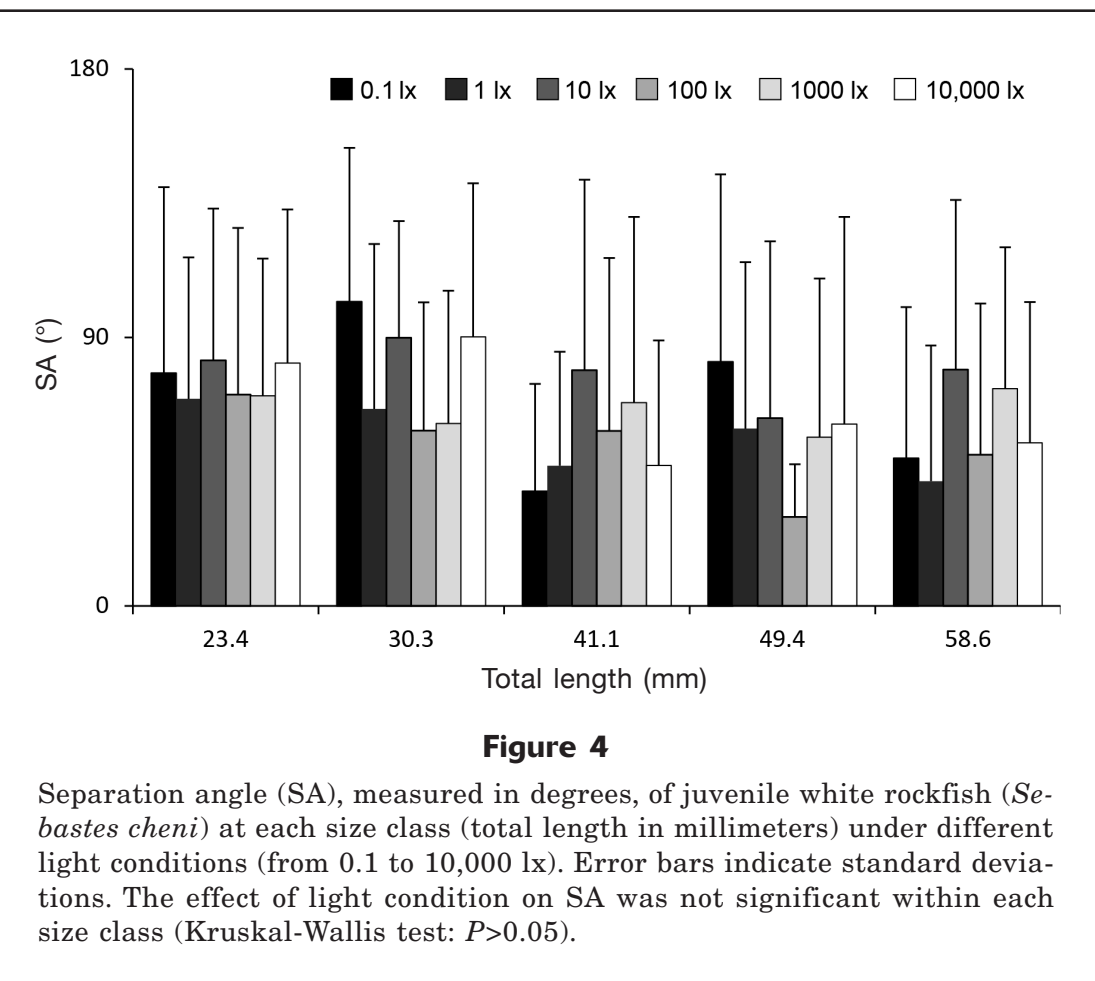




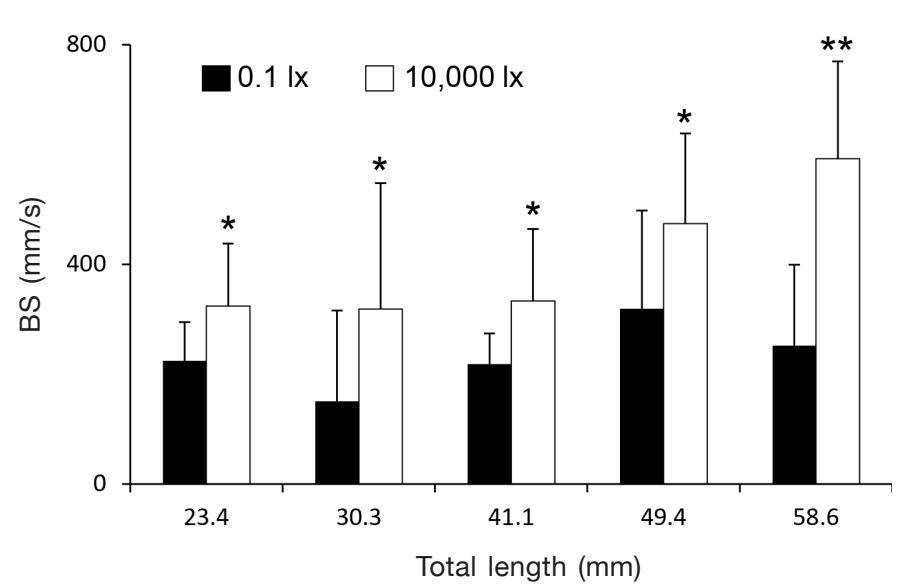

Figure 5

Burst [swimming] speed (BS; measured in millimeters per second) of juvenile white rockfish (Sebastes cheni) in each size class (total length in millimeters). Error bars indicate standard deviations. The effect of fish length on BS was significant only at the light intensity of $10,000 \mathrm{~lx}$ (Kruskal-Wallis test, $P<0.05$ ). Asterisks indicate significant difference in BS between the treatments with different light intensities (Wilcoxon test: ${ }^{*} P<0.05$; ** $P<0.01)$.

\section{Schooling behavior}

The NND and SA have been referred to as indices of the density of individual fish and the orderliness of a fish school (Masuda, 2006; Miyazaki et al., 2000). Development of schooling behavior has been observed to decrease predation risk of larval and juvenile fishes (Masuda, 2006, 2011). The sizes of experimental tanks were expected to affect the NND with smaller values in smaller tank sizes. The NND of juvenile white rockfish at $30.3 \mathrm{~mm}$ TL (tank size: $30 \mathrm{~L}$ ) was greater than values observed for fish at larger sizes (49.4 and $58.6 \mathrm{~mm}$ TL) that were put in larger tanks $(100 \mathrm{~L})$ in our study. These results indicate that the decrease in NND for fish at larger sizes was not attributed to the difference in tank size in our experiments.

Compared with data from tank experiments available for other fish species at similar body lengths and light conditions, NNDs of juvenile white rockfish from our study were greater. The NND (absolute value in millimeters) of white trevally juveniles in a previous experiment was $15.5 \mathrm{~mm}$ (SD 1.4) at $20 \mathrm{~mm}$ TL (Miyazaki et al., 2000), a much shorter NND than that of juvenile white rockfish $(62.5 \mathrm{~mm}$ [SD 27.9] at 23.4 $\mathrm{mm} \mathrm{TL}$ ) in our study under the same light intensity $(0.1 \mathrm{~lx})$. The standardized NND (divided by fish total length) was also smaller in white trevally $(0.75 \mathrm{~mm}$ TL-1 at $20 \mathrm{~mm}$ TL) than in white rockfish $(2.69 \mathrm{~mm}$ TL-1 at $23.4 \mathrm{~mm}$ TL). The decrease in NND with increase in body size (from 23.4 to $41.1 \mathrm{~mm}$ TL) indicates the development of school formation. The ability of white rockfish juveniles to avoid predation through the use of schooling behavior would be minimal during the postsettlement period (about 20-40 $\mathrm{mm}$ TL) compared with the ability of white trevally because that behavior is not well developed in white rockfish.

It has been suggested that development of mechanosensory organs, such as lateral lines, contribute to decreases in NND in school formations of juvenile fish (Masuda and Tsukamoto, 1998). Formation of scales and change in body color both have been reported to occur in cultured rockfishes at about $30 \mathrm{~mm}$ TL, the size at which physiological and morphological metamorphosis is complete (Suzuki and Aida, 1999; Nagasawa, 2001). The decrease in NND observed for fish up to $41.1 \mathrm{~mm}$ TL at all light levels in our study appears to coincide with the size at which white rockfish complete their metamorphosis from larvae to juveniles. For fish in the size classes of 23.4 and $30.3 \mathrm{~mm}$ TL, the NND was shortest under intermediate light intensity (100 lx). Juvenile white rockfish of these sizes are considered daylight feeders (Shoji et al., 2011) and swim faster under high light intensities than under intermediate intensities, when compared with the same size class. It seems that small juveniles cannot form schools with small NNDs under low light conditions because the complete sensory functions of the eyes and lateral lines are undeveloped at the 2 smallest size classes (Suzuki and Aida, 1999; Nagasawa, 2001).

Separation angle of fish in early life stages is a proxy of orderliness of a fish school (Masuda et al, 2003). Japanese anchovy (Engraulis japonicus) juveniles form schools with SAs $<30^{\circ}$ (Masuda, 2011). Juveniles of a piscivorous fish, Japanese Spanish mackerel (Scomberomorus niphonius), form schools in which individuals are more dispersed with an SA of $33-44^{\circ}$ (Masuda et al., 2003). In our study, SAs observed for white rockfish in all length classes and at light intensities tested $\left(>40^{\circ}\right)$ were larger than previously reported SAs of other species. These observations from our study indicate that juvenile white rockfish form loosely aligned aggregations that maintain their body angle in inconsistent directions during the juvenile period.

\section{Antipredator behavior}

Predation rate of juvenile fishes is controlled by the probability of encounter with, and capture by, their predators (Bailey and Houde, 1989). Capture success of predators is affected by the BS of prey fish (Bailey and Houde, 1989). In our study, BS of the juvenile white rockfish under the low light intensity $(0.1 \mathrm{~lx})$ was significantly lower than BS of fish under high light intensity $(10,000 \mathrm{~lx})$ in all size classes tested. In addition, the BS of fish under the highest light intensity increased as white rockfish grew, but BS of fish under lowest light intensity was stable regardless of juvenile 
body size. These results indicate that the effect of juvenile total length on the BS (a speed that allows for prompt reply to predator's attack) is less during night than during day. Small white rockfish juveniles (21.3 $\mathrm{mm}$ TL) in captivity feed during day and are not active during night (Shoji et al., 2011). Larger white rockfish juveniles begin to feed during night at a body size $>80$ $\mathrm{mm}$ TL (at 1 year old) when their major prey shifts from crustaceans to fish (Kinoshita et al., 2014). The low BS observed under low light conditions can be attributed to their low activity during night.

Juveniles of the white rockfish form loosely aligned aggregations and maintain their body angle in inconsistent directions. The ability of white rockfish juveniles to avoid predation through the use of schooling behavior would be minimal because the ability of juvenile white rockfish to school is not well developed during the early postsettlement period (about 20-30 $\mathrm{mm}$ TL). Therefore, juveniles are considered most vulnerable to predation during the early postsettlement period. School formation develops in juveniles with increasing body length, indicating that vulnerability to predation may decrease with growth. The size-selective predation (lower predation rate in larger white rockfish juveniles) observed in natural habitats during night (Kinoshita et al., 2014) could be explained by the development of antipredator behavior by juveniles through improvement in their schooling behavior as indicated by the decrease in NND at $>30.3 \mathrm{~mm}$ TL. In contrast, improvement of swimming performance cannot explain the size-selective predation because BSs were not significantly higher for fish in the larger size classes at the lowest light intensity.

\section{Acknowledgments}

We express our thanks to S. Iwasaki, Y. Chiba, Y. Ogino, other laboratory staff members, and students for their assistance in our experiments. This study was supported partly by the Global Environment Research Fund (E1102) of the Ministry of the Environment, Japan.

\section{Literature cited}

Adams, P. B., and D. F. Howard.

1996. Natural mortality of blue rockfish, Sebastes mystinus, during their first year in nearshore benthic habitats. Fish. Bull. 94:156-162.

Bailey, K. M., and E. D. Houde.

1989. Predation on eggs and larvae of marine fishes and the recruitment problem. Adv. Mar. Biol. 25:1-83. Article

Batty, R. S., J. H. S. Blaxter, and J. M. Richard. 1990. Light intensity and the feeding behavior of herring, Clupea harengus. Mar. Biol. 107:383-388. Article

Blaxter, J. H. S.

1968. Light intensity, vision, and feeding in young plaice. J. Exp. Mar. Biol. Ecol. 2:293-307. Article
Dauble, A. D., S. A. Heppell, and M. L. Johansson.

2012. Settlement patterns of young-of-the-year rockfish among six Oregon estuaries experiencing different levels of human development. Mar. Ecol. Prog. Ser. 448:143-154. Article

Guest, M. A., R. M. Connolly, and N. R. Loneragan.

2003. Seine nets and beam trawls compared by day and night for sampling fish and crustaceans in shallow seagrass habitat. Fish. Res. 64:185-196. Article

Heck, K. L., Jr., and R. J. Orth.

2006. Predation in seagrass beds. In Seagrasses: biology, ecology and conservation (A. W. D. Larkum, R. J. Orth, and C. M. Duarte, eds.), p. 537-550. Springer, New York.

Hindell, J. S., G. P. Jenkins, and M. J. Keough.

2000. Variability in abundances of fishes associated with seagrass habitats in relation to diets of predatory fishes. Mar. Biol. 136:725-737. Article

Houde, E. D.

1987. Fish early life dynamics and recruitment variability. Am. Fish. Soc. Symp. 2:17-29.

Jones, D. T., C. D. Wilson, A. De Robertis, C. N. Rooper, T. C. Weber, and J. L. Butler.

2012. Evaluation of rockfish abundance in untrawlable habitat: combining acoustic and complementary sampling tools. Fish. Bull. 110:332-343.

Kai, Y, and T. Nakabo.

2008. Taxonomic review of the Sebastes inermis species complex (Scorpaeniformes: Scorpaenidae). Ichthyol. Res. 55:238-259. Article

Kamimura, Y., A. Kasai, and J. Shoji.

2011. Production and prey source of juvenile black rockfish Sebastes cheni in a seagrass and macroalgal bed in the Seto Inland Sea, Japan: estimation of the economic value. Aquat. Ecol. 45:367-376. Article

Kamimura, Y., and J. Shoji.

2009. Seasonal changes in the fish assemblage and early growth of the dominant species in a mixed vegetation area of seagrass and macroalgae in the central Seto Inland Sea. Aquac. Sci. 57:233-241. Article

2013. Does macroalgal vegetation cover influence postsettlement survival and recruitment potential of juvenile black rockfish Sebastes cheni? Estuar. Coast. Shelf Sci. 129:86-93. Article

Kinoshita, H., Y. Kamimura, K. Hirai, K. Mizuno, Y. Iwamoto, and J. Shoji.

2012. Vulnerability of juvenile fish to piscivorous fish predators increases during nighttime in a seagrass bed in the central Seto Inland Sea, Japan. Bull. Jpn. Soc. Fish. Oceanogr. 76:24-30.

Kinoshita, H., Y. Kamimura, K. Mizuno, and J. Shoji.

2014. Night-time predation on post-settlement Japanese black rockfish Sebastes cheni in a macroalgal bed: effect of body length on the predation rate. ICES J. Mar. Sci. 71:1022-1029. Article

Laidig, T. E., J. R. Chess, and D. F. Howard.

2007. Relationship between abundance of juvenile rockfishes (Sebastes spp.) and environmental variables documented off northern California and potential mechanisms for the covariation. Fish. Bull. 105:39-48.

Love, M. S., M. H. Carr, and L. J. Haldorson.

1991. The ecology of substrate-associated juveniles of the genus Sebastes. Environ. Biol. Fish. 30:225-243. Article 
Love, M.S., M. Yoklavich, and L. Thorsteinson. 2002. The rockfishes of the northeast Pacific, $414 \mathrm{p}$ Univ. California Press, Berkeley, CA.

Masuda, R.

2006. Ontogeny of anti-predator behavior in hatcheryreared jack mackerel Trachurus japonicus larvae and juveniles: patchiness formation, swimming capability, and interaction with jellyfish. Fish. Sci. 72:1225-1235. Article

2011. Ontogeny of swimming speed, schooling behaviour and jellyfish avoidance by Japanese anchovy Engraulis japonicus. J. Fish Biol. 78:1323-1335. Article

Masuda, R., and K. Tsukamoto.

1998. The ontogeny of schooling behaviour in the striped jack. J. Fish Biol. 52:483-493. Article

Masuda, R., J. Shoji, M. Aoyama, and M. Tanaka.

2002. Chub mackerel larvae fed fish larvae can swim faster than those fed rotifers and Artemia nauplii. Fish. Sci. 68:320-324. Article

Masuda, R., J. Shoji, S. Nakayama, and M. Tanaka.

2003. Development of schooling behavior in Spanish mackerel Scomberomorus niphonius during early ontogeny. Fish. Sci. 69:772-776. Article

Miyazaki, T., S. Shioawa, T. Kogane, R. Masuda, K. Maruyama, and K. Tsukamoto.

2000. Developmental changes of the light intensity threshold for school formation in the striped jack Pseudocaranx dentex. Mar. Ecol. Prog. Ser. 192:267-275. Article
Nagasawa, T.

2001. Early life history of rockfishes (genus Sebastes) in the Sea of Japan. Bull. Jpn. Sea Natl. Fish. Res. Inst. 51:1-132.

Petr, T.

2000. Interactions between fish and aquatic macrophytes in inland waters: a review. FAO Fish. Tech. Paper 396, 185 p. FAO, Rome.

Plaza, G., S. Katayama, and M. Omori.

2002. Abundance and early life history traits of youngof-the-year Sebastes inermis in a Zostera marina bed. Fish. Sci. 68:1254-1264. Article

$\mathrm{R}$ Core Team.

2014. R: a language and environment for statistical computing. R Foundation for Statistical Computing, Vienna, Austria. [Available from http://www.r-project.org, accessed September 2014.]

Shoji, J., S. Toshito, K. Mizuno, Y. Kamimura, M. Hori, and K. Hirakawa.

2011. Possible effects of global warming on fish recruitment: shifts in spawning season and latitudinal distribution can alter growth of fish early life stages through changes in daylength. ICES J. Mar Sci. 68:1165-1169. Article

Suzuki, N., and S. Aida.

1999. Organogenesis and behavioral changes during development of hatchery-reared black rockfish, Sebastes inermis. Bull. Fish. Environ. Inland Sea 1:1-13. 